\title{
Ensaio como canção popular brasileira moderna
}

\section{Essay as modern Brazilian popular song}

\author{
DANILO ÁVILA*
}

Resenha de:

MAMMİ, Lorenzo. A fugitiva. São Paulo: Companhia das Letras, 2017.

N ascido em Roma em 1957, Lorenzo Mammì radicou-se no Brasil na segunda metade dos anos 1980. Segundo ele, até então seu conhecimento de música brasileira se estendia ao que chegava à capital italiana: Chico Buarque, Vinicius de Morais/Toquinho, Tom Jobim, João Gilberto e Villa-Lobos'. Não à toa, esses compositores constituem parte significativa de sua trajetória na crítica musical. Seus dois primeiros textos publicados no Brasil sobre música abordam Villa-Lobos e João Gilberto, ambos encomendados pelo Cebrap e lançados respectivamente em 1987 e 1992². Os textos não guardam qualquer semelhança de análise, como afirma na introdução d'A fugitiva, pois a tarefa do crítico de música erudita e popular é, ao mesmo tempo, "oposta e complementar". No primeiro caso, "trata-se de abrir a caixa preta de um sistema formalmente rigoroso e autorreferente, para mostrar os fios que o ligam à experiência cotidiana do mundo", enquanto que, no segundo, é preciso "acompanhar como a experiência do mundo se torna forma significativa autônoma" (p. 11). Isto é, um movimento oposto, mas que, aos olhos do crítico, carrega uma complementaridade em suas distâncias e diferenças de direcionali-

\footnotetext{
* Danilo Ávila é doutorando em História pela Unesp/Franca. É autor da dissertação de mestrado Hans Joachim Koellreutter: uma experiência de vanguarda nos trópicos (1937-1951). Participa ativamente do Laboratório de Música e Ciências Humanas do Instituto de Estudos Brasileiros (IEB-USP) e faz parte da equipe de reformulação da plataforma Sussurro/Musicon no Centro de Documentação de Música Contemporânea (CDMC/Unicamp). E-mail: danilo.avila@gmail.com

${ }^{1}$ Depoimento dado em conversa sobre A fugitiva (2017) com o Laboratório de Música e Ciências Humanas, realizado no Instituto de Estudos Brasileiros (IEB/USP) em 14 de maio de 2018.

${ }^{2}$ MAMMİ, Lorenzo. João Gilberto e o projeto utópico da bossa nova. Novos Estudos Cebrap, n. 34, p. 6370, nov. 1992; MAMMİ, Lorenzo. Uma gramática do caos - notas sobre Villa-Lobos. Novos Estudos Cebrap, n. 19, p. 103-112, dez. 1987.
} 
dade. Neste sentido, os ensaios mostram "Brasis" totalmente distintos, um dos anos 1920/30 e o outro dos anos 1950. Na mesma medida em que na composição de VillaLobos podemos sentir a ordem social na mudança composicional dos Choros para as Bachianas, o crítico procura mostrar como João Gilberto dá as costas à cidade para, em suas canções, olhar a praia. Ou seja, uma sublimação da civilização praieira em forma de canção - na sua completa indistinção entre o profissional e o amador, o público e o privado -, que se opõe assim ao industrializado jazz estadunidense.

Dada esta distância entre os métodos, nada mais natural que separar "a fugitiva" em dois eixos, um para o popular ("Primeira parte") e o outro para o erudito ("Segunda parte") - quem sabe assim a captura melhor, mesmo condenando a tarefa ao fracasso desde o princípio. Enquanto o segmento erudito está apenas enfileirado na sequência de publicação, aqueles sobre música popular, aos quais me atenho nesta resenha, seguem uma cronologia histórica. Ainda que, para os leitores de Mammì, a "Primeira parte" não seja inédita ${ }^{3}$, prevalece na coletânea - daí a sua originalidade - uma concepção específica de desenvolvimento histórico da canção brasileira. Ela é orientada pelo autor na sucessão dos textos, descortinando a organicidade da forma que quer apreender ${ }^{4}$.

Percebe-se que não faria mesmo sentido colocar o texto de João Gilberto em primeiro lugar. Havia um anterior imprescindível: Dorival Caymmi. O curto ensaio de uma página e meia guarda um tom de abertura de concerto ou, para quem está mais familiarizado com a estética carnavalesca, um "abre-alas". O ensaio tem uma pontuação breve. Raras são as frases que se estendem à terceira linha. Tal gesto mimetiza o cancioneiro Caymmi, no qual as frases "são curtas e estáveis" (p. 15). Além disso, nada carece de muita explicação ou justificação. É porque é. Melhor, é

\footnotetext{
${ }^{3}$ Os textos de Lorenzo Mammì dedicados ao eixo "Música popular" foram publicados originalmente nos seguintes periódicos e livros: Dorival Caymmi. In: NESTROVSKI, Arthur (org.). Música popular brasileira hoje. São Paulo: PubliFolha, 2002, p. 73-74; João Gilberto e o projeto utópico da bossa nova. Novos Estudos Cebrap..., op. cit.; No mesmo lugar, muito à frente. Folha de São Paulo, Ilustríssima, 10 jul. 2011; Prefácio. In: CANCIONEIRO Jobim. Rio de Janeiro: Jobim Music/Casa da Palavra, 2000, p. 1319; Os sonhos dos outros. In: NESTROVSKI, Arthur (org.). Lendo música. São Paulo: PubliFolha, 2007; A era do disco. Piauí, n. 89, fev. 2014.

${ }^{4}$ Caso haja interesse pela última parte, publiquei uma resenha em tom jornalístico para o site Música e Sociedade. Cf. ÁVILA, Danilo. O jogo da arte musical: A Fugitiva de Lorenzo Mammì. Disponível em: $<$ https://musicaesociedadenews.com.br/o-jogo-da-arte-musical-resenha-a-fugitiva-de-lorenzomammi/>. Acesso em: 20 jun. 2018.
} 
porque acontece. Para narrar o criador das canções praieiras é preciso deixar a exatidão de lado. "A função [dos acordes, e também da vida] perde importância em relação ao valor de afeição. Acontece que o acorde está lá, acontece que a gente gosta" (p. 15). "Intermediária entre a história e a pré-história, natureza e cultura", Caymmi "é o pai" de um lugar e de uma carga utópica na música brasileira, em que o futuro e o passado, a modernidade e o arcaico, "convivem em paz". Essa história é carioca, mas alguns de seus maiores representantes são baianos, tornando indistinta a gênese do ser carioca com "barquinho, cantinho e violão" (p. 16).

Incumbido da missão de continuar o legado desta utopia, João é "o filho". Se em Caymmi as canções "acontecem", em João Gilberto tornam-se "projeto" com nome e sobrenome: bossa nova. Se a conversa de Caymmi remete a um folclore inventado, muito à sua maneira, a conversa do violonista de Juazeiro não dispensa "as lojas de discos importados que distribuíam Stan Keaton e Frank Sinatra" e nem certa tradição de música popular que vai desde Mário Reis, Ary Barroso até - claro Caymmi. No ensaio sobre João Gilberto, Mammì demonstra um "método" dialético entre aspas, pois tudo que se pretende dialético quer romper a esfera do método através de uma ensaística. Nesta embolada, delimita um padrão de análise para essa história da música popular brasileira que procura narrar. Esse modo de analisar é feito de três tensões: uma interna ao mundo do qual o objeto participa (João Gilberto e Tom Jobim), a outra externa (João Gilberto e o jazz), e uma terceira no próprio objeto ao longo do tempo - o Jobim de "A felicidade" não é o mesmo de "Sabiá". Só se compreende as canções na comparação com outros artefatos culturais, sobretudo com outras canções. Elas podem ou não estar aproximadas no tempo, no gênero ou no estilo. Não há qualquer temor em lançar mão de uma referência à Living Room Music (1940) de John Cage para ajudar a pensar a música de apartamento moldada pela bossa nova. No entanto, enquanto Cage procurava percutir todos os itens da sala, João Gilberto, em chave oposta, quer experimentar suas possibilidades acústicas ao trocar a tapeçaria, mensurar até onde pode cantar baixinho, um gesto de esmero com o som que produz.

É com esse mesmo esmero que Mammì sustenta suas comparações, buscando a medida exata. Sua construção frásica é paratática, é no lado-a-lado que se 
esclarece. "Bossa Nova é classe média carioca”, afirmação do primeiro parágrafo do ensaio de 1992. Mas esse lado-a-lado é recurso para a crítica, conduz à provocação, ou seja, não se trata de determinar causalidade. É sempre ambíguo, ou melhor, dialético. Para quem lê isso sem conhecer o autor, imaginará que o que vem por aí é uma condenação da bossa nova por seu estilo de vida Zona Sul carioca, denotando uma "sociologia apressada". Ledo engano. É exatamente aí que reside sua "novidade e força”, pois há uma ginga, um "conforto que não se identifica com o poder", "uma vida sofisticada sem ser aristocrática" (p. 17). Essa contemporização da bossa nova como fruto da classe média carioca sugere seu desconforto para com análises que tomam tal relação de modo reducionista. (Sem ser citado no ensaio, o primeiro nome que vem à mente não poderia ser outro senão José Ramos Tinhorão).

$\mathrm{O}$ "método" de Mammì, para funcionar, parece ter a necessidade da tensão entre projetos concorrentes. João Gilberto é constantemente confrontado com o jazz estadunidense na mesma medida em que há uma tensão entre ele e Tom Jobim no nascimento da bossa nova. Na primeira tensão, o jazz, insígnia de um país produtivista e industrial, é comparado à bossa-nova como símbolo de uma capital não produtiva, Rio de Janeiro. Como a canção de João se aproxima dessa estrutura social e política? Segundo o crítico, há uma busca pelo coloquial na sua forma de interpretar as canções, sempre à procura das nuances melódicas que estão no nascer da fala e não tem grandes solavancos, enquanto que o "Chet Baker cantor imita o Chet Baker trompetista", aproximando-se mais do instrumento do que propriamente da fala. "O pulso da bossa nova, e, sobretudo, o de João, é uma pulsação doméstica, o correr indefinido das horas em que ficamos em casa" (p. 26). Se nas big bands o espírito fordista é latente, na bossa nova impera a calmaria do ambiente residencial.

A música de Tom Jobim também guarda suas distâncias do jazz através de suas melodias tortuosas que seriam impensáveis em qualquer jam session, pois são difíceis de improvisar e, em termos de desenvolvimento, não variam ("Quanta gente existe por aí que fala tanto e não diz nada"). Essas melodias são constantemente reharmonizadas, rearranjadas a cada repetição, fazendo "da redundância um estilo". Neste sentido, Jobim é entendido nas aproximações com Chopin - "autossuficiência do canto" - e Villa-Lobos, mestre do qual é "seu melhor discípulo" (p. 20). Construí- 
da a constelação na qual paira a estrela-maior, Jobim, Mammì segue para a confrontação com João. Eles possuem um mesmo ponto de partida na "autossuficiência do canto", mas,

[...] enquanto Jobim a cria [a melodia] mediante uma encenação, apresentando uma estrutura complexa só para fazê-la recuar, quase desaparecer, frente a linha melódica, João Gilberto tenta reproduzir na melodia todos os parâmetros do som, sem que por isso a voz se torne instrumento - ao contrário, aproximando sempre mais o canto à fala (p. 21).

Há algo de estrutural que paira nas afirmações de Mammì sobre a bossa nova. É como se ela participasse das contradições culturais brasileiras como um sintoma, algo que é dado muito lá atrás e prevê as mazelas. Isso salta aos olhos quando nosso autor recorre a Mário de Andrade para mostrar como a métrica 6/8 - símbolo rítmico do movimento - já era detectada no jeito popular de se cantar o hino nacional. "A raiz não está numa escolha estilística, mas na prosódia natural da língua” (p. 23). No outro texto sobre João Gilberto ("No mesmo lugar, muito à frente") - agora colocado em paralelo a Miles Davis - segue a sua busca pela medida exata. Note-se, para isso, que todos os cancioneiros escolhidos por Mammì complexificam progressivamente suas obras e confrontam seus lugares estáveis a todo o momento.

Para se ter uma noção, João Gilberto está “fora da fábrica, mas não dentro do circo" (p. 35), "seu lugar de eleição é a beira-mar, dando as costas à cidade, mas sem entrar na água. Seu tempo é à tardinha, tarde demais para fazer alguma coisa, cedo demais para sair" (p. 31). Neste ensaio, João tem dupla paternidade: Ary Barroso, “expressão mais plena da autoconsciência técnica e poética da música popular brasileira", e Dorival Caymmi, "que pusera um estilo de composição muito arrojado a serviço de uma fala popular, aparentemente folclórica" (p. 32-33). A intenção é clara: mostrar que não é na relação direta com o jazz que se entende a bossa nova. É preciso pensar em muitos astros menos visíveis que pairam nessa constelação - de Godard a Miles Davis. Este último surge como quem introduziu um dado ancestral nesse ritmo industrial do jazz ao lançar Kind of blue (1958) e, com esse gesto, se aproxima de João, que tenta mesclar, a seu modo, "alta tecnologia e transe, o laboratório e a tribo" (p. 36). 
Até aqui já havia uma ideia sobre a canção de Jobim, mas ela só fazia sentido na relação com João. No "Prefácio ao Cancioneiro Jobim", a constelação jobiniana ganha em número de astros. A João Gilberto, Chopin e Villa-Lobos juntam-se Debussy e o jovem Chico Buarque. Em Jobim, a letra é o fundamento. Mammì estabelece uma relação entre a composição do maestro e a necessidade de uma letra, mesmo em seus momentos puramente instrumentais. "O fato de ter se cercado de letristas de sensibilidade musical excepcional (Vinicius de Morais, Chico Buarque, etc.), e de ter sido ele próprio um excelente letrista, não é apenas um ponto de força, mas uma necessidade de sua obra" (p. 39). Nisso se distancia mais uma vez de João Gilberto, pois enquanto a criação deste é puramente musical, a canção de Jobim sugere letras que, por sua vez, sugerem "pinturas sonoras, verdadeiros madrigalismos" (p. 40). É na análise dessas melodias de Jobim, extensas e assimétricas, com base no canto, que se adensa sua proximidade com Villa-Lobos, sobretudo aquele "dos movimentos lentos das Bachianas" (p. 42). Para Mammì, não há como não pensar em Debussy quando ouvimos canções de Jobim como "Imagina" (parceria com Chico Buarque), assim como não e possível deixar de perceber Chopin (Prelúdio em Mi menor) em “Insensatez".

Nascido italiano, Mammì aparenta se desvincular do seu "lugar de fala" expressão tão corriqueira nos dias de hoje - num primeiro momento para perceber as inflexões de nossa cultura musical, mas, num segundo momento, remete essas inflexões à influência da cultura musical europeia e estadunidense. Um gesto de reconhecimento de que as ideias viajam, mas que não são as mesmas nem brotam do vácuo. “O que faz a grandeza da música popular brasileira não é a existência de uma linguagem nacional 'pura', nem de gêneros estritamente populares, mas a capacidade de fundir e adaptar técnicas e estilos das proveniências mais variadas" (p. 44). Esse gesto visa a mostrar que em nossa terra nunca houve uma separação muito nítida entre as culturas "baixas e altas", por mais que houvesse esforços à época da Primeira República para que fossem cindidas - por exemplo, "coros de escravos eram recrutados para cantar ópera, e um músico de banda podia acompanhar a procissão do Divino num dia e, no dia seguinte, participar da encenação de um drama de Verdi" (p. 44). 
Mesmo a diferença interna entre os projetos de Jobim e João Gilberto não descaracteriza o propósito social primeiro da bossa nova. No entendimento de Mammì, ela "expressa perfeitamente uma ascensão sem esforço [...], a volta à primeira parte da canção é regresso a um lugar que não é mais o mesmo, porque o tempo passou à nossa revelia" (p. 47). Mas esse é o Jobim de "Chega de saudade" e "A felicidade". O Jobim de "Sabiá", como já havia antecipado, é outro. "Sabiá" surge em um momento em que "a televisão transforma os músicos em heróis, portadores não apenas de um novo gosto musical, mas também de novos comportamentos com o público" (p. 50). A ideia deste segundo ensaio sobre Jobim é pensar uma tensão entre o "Jobim anos 50" e o "Jobim anos 60". Este último, com "Sabiá", superou VillaLobos - que, segundo Mammì, não compõe, sobrepõe (p. 127-142) - no artesanato harmônico e está muito mais próximo da composição de canções de câmara. Nesta canção se dá uma outra superação em relação ao mestre, mas por parte de Chico Buarque. $\mathrm{O}$ autor traz elementos para que possamos pensar a ascensão de Chico como letrista através das parcerias com Jobim. Na opinião comum, Chico seria totalmente apolíneo e se voltaria apenas para as coisas belas, argumento que Mammì nega com veemência, inclusive contestando o legado de Vinicius de Moraes normalmente atribuído ao primogênito do nosso historiador mais célebre ("seu estilo não é em nada subserviente ao de seu predecessor"). A adjetivação de Vinicius é generosa, enquanto que o filho de Sérgio Buarque de Hollanda quase que a abole em suas letras, pois opta pela "palavra dita entre os dentes" (p. 54).

"Sabiá" guarda uma contradição interna entre o movimento da letra, que repete "vou voltar" algumas vezes e assim reafirma o movimento que é colocado em questão pela dubiedade harmônica, que nunca se assenta sobre um centro tonal; ou seja, nunca volta propriamente, gerando uma tensão entre a forma e o conteúdo da canção (p. 57). A canção narra o exílio do compositor. Mammì prefere a versão em que "não há volta", que rodeia em torno da "palmeira que já não há", da "flor que já não dá" e culmina nas "noites que eu não queria". Essa versão foi gravada em Stone flower (1970). O desfecho feliz em outras gravações de Jobim, à revelia das opiniões de Chico, foi infeliz segundo Mammì. Não soa orgânica à canção uma colagem que desfaz a pesarosa separação. À medida que este Jobim, desterrado e infeliz, nada tem 
a ver com o compositor despojado em seu habitat natural de "A felicidade", em "Águas de Março", o "oposto complementar" de "Sabiá, , Jobim finalmente volta pra casa" (p. 62).

Toda escolha de objeto de Mammì carrega em si o seu contrário complementar. É como se cada ensaio dissesse sobre um momento significativo de uma linha de desenvolvimento da canção brasileira moderna, e nele contivesse o seu desenvolvimento a partir de parâmetros internos. Em Caymmi está João. Em João está Jobim. Em Jobim está Chico. Essa tríade final, salvo o "pai", poderia se equiparar à importância da tríade de fundação e formação da música sinfônica Haydn, Mozart e Beethoven, em termos de canção brasileira. Caymmi é Bach. Nesse sentido, quando chega Luiz Tatit (“Os sonhos dos outros: sobre 'Sonhei', de Luiz Tatit", p. 84-103), esse material musical já findou o seu ciclo de desenvolvimento, portanto cabe parodiá-lo. Não por acaso, para iniciar o "Prefácio ao Cancioneiro Chico Buarque" - que, em A fugitiva, antecede "Os sonhos dos outros..." -, Mammì retoma a provocação lançada por Chico na seção Ilustríssima da Folha de S. Paulo, em 2004, na qual o músico dizia que a canção, tal qual a conhecemos - devido ao rap e outros gêneros -, estava em vias de esgotamento. Como contraponto, Tatit, em $O$ século da canção, livro lançado no mesmo ano, afirmava que o século XX teria sido o século da canção, porém com um tom mais otimista com relação à continuidade da forma.

Dentro desta teoria da história da canção, Chico ocupa a posição de uma "revolução menor", sendo, como todos os objetos escolhidos pelo autor ítalo-brasileiro, "difícil de definir". Não arrebentou com as linhas entre a vanguarda e o pop (gesto tropicalista), nem refinou a tradição ao extremo (p. 66). Segundo Mammì, ele é quem melhor aproveitou o material herdado, fazendo-o refletir sobre si. Um dos recursos utilizados é a indefinição de seu eu lírico. Chico constantemente interpõe alguém homem ou mulher - entre a canção e o intérprete (p. 67). Um exemplo é o caso da canção "Pedro pedreiro", um saber arcaico que a industrialização explora, mas não valoriza. Alguém que vê a industrialização chegar e já mensura os prejuízos (p. 68). Esse é um recurso muito valioso em tempos de canções que moldavam comportamentos pessoais e políticos, como eram os anos 1960 e 70 (p. 63-64). 
A comparação de Chico com o seu "maestro soberano Antônio Brasileiro"5 não poderia faltar. Ao contrário da moda na bibliografia corrente, que é aproximar os dois, Mammì procura distâncias. "Desalento" ("Corre e diz a ela / que eu entrego os pontos") é uma postura oposta à de "Chega de saudade" ("Vai e diz a ela / que sem ela não pode ser"). “Onde a bossa nova praticava o exercício da dupla negação, da possibilidade sempre deixada em aberto, Chico Buarque deliberada e decididamente se precipita" (p. 73). Se a canção bossa-novista evita acabar, Chico é afeito ao pontofinal. Mais uma tensão entre os projetos de Chico Buarque e Tom Jobim está na comparação entre "Flor da idade" e "Garota de Ipanema". A garota de Chico é suburbana, "passa e balança", a harmonia vagueia em um langoroso "tom menor". Mas é preciso atentar para a harmonia banal que sustenta toda a canção, recurso para uma "alegria verdadeira". Na referência à "Quadrilha", de Carlos Drummond de Andrade, Chico alia "alta poesia e conversa cafajeste" ao modificar e pensar relações entre pessoas do mesmo sexo (p. 76). A repetição em Chico está tanto para uma intensificação quanto para um esvaziamento, portanto é mais ambígua que a de Jobim. A relação da repetição está entre seu preenchimento, que dá vivacidade ou um tom anódino e mecânico, mostrando, assim, a liquefação moderna: “Vai contra o tempo mecânico ou mostra o seu automatismo" (p. 72-73).

O Chico de "Pedro Pedreiro" não se parece com o de "Construção", e deles não temos nenhum vestígio nos discos da década de 1980 como Vida. Mammì está à procura do singular, esta é a medida exata de seu pensamento, somente possível graças à escolha de objetos tão complexos. Em "Pelas tabelas" vemos uma música que a todo o momento coloca um sujeito na contramão dos acontecimentos gerais, não necessariamente contradizendo-os (p. 77). Os discos lançados na segunda metade dos 80 presenciam um momento de exposição política, fazendo palanque para FHC (1985) e para Lula (1989). Ao mostrar as nuances de Chico, Mammì percebe que o cancioneiro constrói uma autonomia em sua música, que não é nem samba nem bossa-nova e tampouco MPB no estilo tradicional, mas remete à sua própria história da canção. Exercício viável apenas a quem pegou a linha de desenvolvimento da can-

\footnotetext{
${ }^{5}$ Referência à canção "Paratodos", de Chico Buarque, gravada em seu disco homônimo, de 1993. 
ção popular brasileira já formada. Chico, e também Caetano Veloso, são vistos como aqueles que fecham esse desenvolvimento.

Mas quem são os agentes dessa canonização? É isso que o ensaio sobre Luiz Tatit procura responder, apesar de o subtítulo despistar, já que aponta para apenas uma canção específica, cuja letra dividida nas epígrafes contém cada um dos sete itens do ensaio - apenas o último, breve, é dedicado a pensar, de fato, a canção "Sonhei". Mammì precisa de um panorama comparativo. Neste caso, ele se serve da trajetória de Paulinho da Viola aliada à construção da instituição MPB, assunto largamente abordado pela bibliografia sobre o tema. No entanto, o autor narra com simplicidade e irreverência um projeto canônico e carioca, para tensioná-lo, em seguida, com o projeto paulistano - sem ligação com o interior do Estado ou o imigrante - de uma música popular urbana. Mais uma oposição, desta vez entre Luiz Melodia (“Um carioca sempre pode estabelecer uma continuidade hipotética, se não real, com a cultura dos morros”) e Itamar Assumpção ("um paulista não tem nenhum morro atrás de si"). Importante ressaltar como hoje toda uma nova geração de músicos paulistanos tem nessa tradição uma "continuidade hipotética". Mas essa referência agora não se dá apenas regionalmente, mas no âmbito dos que seguiram o experimentalismo na música popular, como, por exemplo, Jards Macalé e Luiz Melodia, no Rio, Walter Franco, Tom Zé, Itamar e Arrigo Barnabé, em São Paulo.

Ao passo que Paulinho da Viola é a voz por onde o cânone carioca se molda, Tatit buscará um para chamar de seu nas ironias de Adoniran. Segundo Mammì, na canção paulista paira um ethos irônico ("em sentido humorístico"), uma "deselegância proposital e lunática" (p. 88). À semelhança de Nuno Ramos, que associa Paulinho a Leonardo da Vinci (p. 84), Mammì emprega uma analogia com as artes plásticas e acredita que tanto o carioca Paulinho quanto o paulistano Tatit estão mais próximos dos pintores maneiristas - sem sentido pejorativo, como geralmente se atribui. “Essa postura não é nostálgica ou meramente derivativa: a distância do modelo não é defeito [...] na medida em que proporciona um grau de consciência que o simples pertencimento à tradição não permitiria" (p. 85). Significa pura e simplesmente que "cada obra carrega nas costas todas as obras que foram criadas antes dela". E Mammì sente esse peso em Tatit. Mais uma referência externa para a constelação. 
Essa posição de Atlas em Tatit se revela desde as suas primeiras composições com o Grupo Rumo, como em "Canção bonita", que é autorreferente e metaforiza sua condição de canção gravada. Não há uma construção clássica de canção nas letras e músicas do Rumo, já que elas se apresentam "como fragmentos recortados diretamente da fala cotidiana e carregando consigo toda a bagagem de gestos e expressões do falante; por isso funcionavam melhor no palco do que no disco" (p. 91). Elas precisam da performance clownesca para dar sentido à canção. Para Mammì, Tatit é um quase-cancioneiro, "quase fala, quase canção, quase sentimento" (p. 93-94). Ou, ainda, é como se "cada canção olhasse no espelho e compartilhasse a legenda do cachimbo de Magritte: Ceci n'est pas une chanson" (p. 89).

“Se a voz de Paulinho da Viola lembra as paisagens distantes de Leonardo, a de Tatit poderia ressoar numa praça de De Chirico". Voltando à hipótese principal nesta resenha, Mammì precisa tanto de comparações externas ao objeto quanto de comparações internas. Não há como entender o Tatit de "Canção bonita" como o mesmo Tatit de "Haicais". Este alcança aqui um desenvolvimento da densidade da rima e da assonância que estava presente apenas de modo incipiente na sua primeira canção. E este também não é o mesmo em "Sonhei", olimpo da canção, e por isso fala por si só. “É uma canção simples, se é que ainda há canções simples [...]. É canção de maturidade, porque não há álibi" (p. 102-103). Nela, Tatit se reencontra com a melodia que é "melodia mesmo", sem ambiguidade com o tom da fala. É como uma "canção de Roberto Carlos" (p. 102). No entanto, como não poderia deixar de ser, senão não seria Tatit, o estranhamento labiríntico fica presente na temática: “O sonho é o sonho de outro/ e nosso sonho é sonhá-lo [...]. Se eu o pego, ele evapora/ se ele me pega eu perco" (p. 103). Assim como a música, o sonho é tudo que escapa, fugitivo.

Enquanto ao longo desses ensaios pudemos acompanhar a trama que narra a ascensão e queda de uma forma artística, em "A era do disco", o último ensaio da seção popular, vemos o vai-e-vem do suporte que sustentou essa hegemonia da forma-canção, o long-play. Contudo, apesar de sua hegemonia estar intrinsicamente ligada à da canção popular brasileira na construção de uma identidade e de uma forma unitária, seu impacto não se restringe a ela. Sem o disco, “um apaixonado [...] teria a chance de ouvir a Nona de Beethoven, por exemplo, duas ou três vezes na vi- 
da, se tanto" (p. 108). O mesmo se pode afirmar para as récitas das grandes óperas. No caso da música "pós-weberniana", que evita qualquer repetição, o suporte se torna uma maneira de dar coerência e entendê-la, pois é custoso apreender suas nuanças em uma primeira escuta. Uma pergunta sobressai: Por que o LP é ainda hoje utilizado e revivido, sendo que tiveram tantos outros suportes digitais de diferentes matizes para substituí-lo? No long-play, diferente dos outros discos de menor duração, o suporte deixa de ser mero receptáculo para um determinado som e passa a ser "um mundo onde concorrem diferentes linguagens, um sistema de códigos, um modelo de vida" (p. 117). Para a geração que viveu dos anos 1960 aos 80, assim como a “canção MPB", o disco era uma forma de identidade, sua discoteca definia a que grupo pertencia, assim como era motivo de disputa em fins de relacionamentos ("Mas fico com o disco do Pixinguinha, sim! / o resto é seu"6). Como o define Mammì, o long-play é "sociabilidade objetivada". E isto só foi possível devido à sociedade do consumo.

Difícil estabelecer um marco fixo, mas, com certeza, em termos de alcance, potência e autonomia, o LP Sgt. Pepper's (1966), da banda inventada pelos Beatles, Lonely Hearts Club Band, é a maior representação de uma cultura musical que deixou de ter sua predominância em shows e concertos rumo a uma centralização na experiência do gravado. Mammì desenvolve uma análise detida do disco a partir dos seus recursos de estúdio, dando ênfase ao protagonismo do produtor musical da banda, George Martin, fundamentando nesse disco uma dialética da sociedade de consumo entre o pop e a vanguarda, entre a sociedade de consumo e os valores revolucionários (p. 118-121). No caso do LP, as comparações estão aí com seus antecedentes de goma-laca e 78 rotações - de duração limitada e difícil conservação -, assim como com o CD. Com este, porém, "algo deu errado", pois o CD não ofereceu mudança significativa dentro do comportamento como o fez o seu pressupor, sobretudo por uma predominância do consumo. Isto é, o LP, pensado inicialmente para apenas ser um suporte, cumpriu um papel protagonista como forma artística.

LP e MPB, duas formas artísticas inseparáveis que são narradas em um trajeto rumo à autonomia. Assim é até que alcancem um certo ápice, e depois colhem

\footnotetext{
${ }^{6}$ Referência aos versos de “Trocando em Miúdos", do disco Vida (1980), de Chico Buarque.
} 
seus reveses simultaneamente. A frase diz respeito ao disco, mas com certeza pode se estender à canção popular brasileira moderna que gostamos de chamar de MPB. Ora, "quase sempre, um gênero ou uma técnica adquirem plenamente o estatuto de grande arte quando seu contexto original e sua própria necessidade produtiva desaparecem" (p. 124). Se no caso do LP essa é uma consciência tardia devido à falibilidade dos outros suportes, no caso da tradição canônica de música popular moderna esse é um fato atestado há bastante tempo. O ensaio como forma se torna ensaio como canção, um campo minado, fugaz, provocativo, autorreferente e irreverente. 